ried away from the winter quarters, and the relief expedition ought to be able to search independently for the ice-bound Endurance and for the party or parties left on shore. There would obviously be a much better chance of success if two vessels could be employed-one to search the coastlands, and the other to scour the sea along the probable lines of drift of the Weddell Sea pack. From the observations of the Scotia in the Weddell Sea the prevalent wind direction there appears to be from the east, so that some belt of "land water" may be fairly persistent off Coats Land and the drift of the ice may be westward; but knowledge of meteorology in the Weddell Sea is so scanty that forecasts as to the usual drift of the ice would command but little confidence and may be falsified by an unusual season. The commander of the relief expedition should be at liberty to select his own route.

Sir Ernest Shackleton has met with very bad luck from the weather. His proposed transcontinental sledge journey was a daring and difficult undertaking. He had, however, considered all its possibilities, and it promised a fair chance of success; but his plans may have been deranged at the outset by the exceptionally unfavourable season. The ice conditions in the Weddell Sea may have prevented his starting forth on his great adventure. No time must be lost in organising the expedition to take him the help which he and his colleagues may sorely need. In addition to the return of the Aurora to Macmurdo Sound, two vessels, if possible, should be sent to the Weddell Sea, for the area that will have to be searched is vast, the clues are uncertain, and the season is short.

\section{THE APPLICATION OF MATHEMATICS TO EPIDEMIOLOGY.}

$\mathrm{T}$ may seem remarkable that serious attempts 1 to elucidate the mysteries of epidemic disease with the help of mathematical methods should only have been made within the last sixty years, and, even when made, should have been confined to the efforts of a very small number of students. In the seventeenth and early eighteenth centuries, the school of which Borelli was the most famous exponent endeavoured to bring much less promising medical fields under mathematical cultivation, while Sydenham's exposition of the principia of epidemiology would, one might have thought, have suggested to the founders of our modern calculus of probabilities that here was indeed an opportunity for them. No doubt, however, the explanation is to be found in the absence of statistical data, without which mathematical mills are forced to stand idle. It is of interest to recall the fact that the solution of a problem which took its rise in the failure to publish certain detailed statistics reveals a method which might have been generalised. We allude to Daniel Bernoulli's work on smallpox. ${ }^{1}$

$\mathrm{His}$ solution was as follows :-

If $x$ denote the age in years, $\xi$ the number who survive at that age out of a given number

1 See Todhuriter's "Histcrv of the Th-ory of Probability," $F$. 225. NO. 2429, VOL. 97] born, $s$ the number of these survivors who have not had smallpox, and if in a year smallpox attacks I out of every $n$ who have not had the disease, while I out of every $m$ attacked dies, then the number attacked in element of time $d x$ is $s d x / n$ and we have:-

$$
-d s=\frac{s d x}{n}-\frac{s}{\xi}\left(d \xi+\frac{s d x}{m n}\right) \text { or } \frac{s d \xi-\xi d s}{s^{2}}=\frac{\xi d x}{n s}-\frac{d x}{m n} \text {. }
$$

Substituting $q$ for $\xi / s$, we have $d q=\frac{m q-1}{m n} d x$, so that $n \log (m q-\mathrm{I})=x+$ constant, and ultimately, since when $x=0, s=\xi$,

$$
s=\frac{m \cdot \xi}{(m-\mathbf{I}) e^{\frac{x}{n}}+\mathrm{I}} .
$$

This investigation contains the germ of a method which, as Sir Ronald Ross has brilliantly demonstrated, might be applied to the study of the succession of cases in an epidemic. Nobody, however, took the hint, and the real history of mathematical epidemiology begins with Farr, whose work on these lines has been made familiar to the present generation by Dr. John Brownlee. Modern researches fall into one of two classes. On one hand, those directly or indirectly inspired by the epoch-making discoveries of Prof. Karl Pearson in the theory of mathematical statistics; on the other, the independent investigations of Sir Ronald Ross.

Prof. Pearson's development of a family of frequency curves, including the Gauss-Laplace or normal curve as a particular case and capable of describing effectively distributions very far indeed from normal, enabled statisticians to deal with a wide range of frequency systems, and it naturally occurred to some to use this method in the study of epidemics. Frequency curves have been fitted by Brownlee, ${ }^{2}$ Greenwood, ${ }^{3}$ and other medical statisticians to different epidemics, the most extensive work in this direction having been that of Brownlee. Much of this work was descriptive; that is to say, the object was in the first place to graduate the statistics, and, if possible, to classify epidemics on the basis of the type of curve found. So far as graduation is concerned, the results have been fairly satisfactory, but it proved to be impossible to effect any useful classification, the only result that emerged being that Pearson's Type IV curve was more commonly encountered than any other. The more fundamental problem of epidemiology, viz., that of discovering the law of which the epidemic, whether viewed in its temporal or spatial relations, is an expression, could scarcely be solved in this way. Brownlee, however, was by no means content with the mere graduation of statistics. Following Farr, he surmised, for reasons explained in his papers, that the theoretical curve of an epidemic in time or space should be normal, and that any practical departure from normality should be susceptible of an explanation capable of expression in terms of a function of the

2 Proc. Roy. Soc. Edin., 1906, xxvi., 484 ; ibid., r911, xxxi., 262 3 Journ. Hygiene, r9זr, xi., 96 ; Proc. I7th Inter. Congress Med., r913, Sect. 18. 
normal function. By supposing that a constant of the theoretical normal curve, viz., its standard deviation, was itself a variable, and assuming for the latter a convenient form, he succeeded in obtaining a curve which effectively described certain symmetrical epidemics.

Brownlee did not, however, obtain any function which satisfactorily accounted for the marked asymmetry which characterises many epidernics. It is an interesting illustration of the way in which apparently disparate problems are interconnected that his work owes much to the remarkable memoir of Pearson and Blakeman on random migration, a memoir inspired by the problem of mosquito distribution suggested to Prof. Pearson by Sir Ronald Ross. These researches, then, which began in the a posteriori study of statistics and were continued on the $a$ priori assumption of a normal function being at the root of the problem, have carried us some way, but have not so far provided us with a satisfactory mathematical law of epidemics. Sir Ronald Ross, whose interest in the subject dates from so long ago as I899, and whose latest contribution has just been published, followed a different path. Avoiding any presuppositions as to the form which the law should assume, he looked at the problem as one of transfer, viz., of mutual interchange between groups of affected and unaffected individuals, an interchange complicated by the subjection of each group to certain rates of natality, mortality, emigration, and immigration. Being at first specially concerned with the case of malaria, he formulated the problem in the second edition of his treatise on the prevention of malaria (pp. $65^{1-686}$ ) in a system of difference equations, the solution of which should provide the required law. A summary of this work appeared in Nature of October 5, I9II, under the title "Some Quantitative Studies in Epidemiology." In the paper before us, ${ }^{4}$ these ideas have been extended and clothed in a more convenient mathematical form.

Sir Ronald Ross's method may be illustrated by summarising the simplest of his cases. If $P$ be the whole population, $x$ the ratio of affected to all members, $v$ and $\mathrm{V}$ measures of the variation due to mortality, natality, immigration, and emigration of non-affected and affected persons respectively, and if the proportion affected in time $d t$ be $h . d t . P$ where $h$ is a constant, then we have the following system of equations:-

$$
\begin{aligned}
& d \mathrm{P} / d t=v \mathrm{P}-(v-\mathrm{V}) x \mathrm{P} \\
& d x \mathrm{P} / d t=h \mathrm{P}(\mathrm{I}-x)+(\mathrm{V}-\mathrm{N}-r) x \mathrm{P} \\
& d x \mathrm{P} / d t=x d \mathrm{P} / d t+\mathrm{P} d x / d t .
\end{aligned}
$$

Eliminating $d x \mathrm{P} / d t$ and $d \mathrm{P} / d t$, we have :-

$$
d x / d t=h-(h+v-\mathrm{V}+\mathrm{N}+r) x+(v-V) x^{2} .
$$

If, now, $v=\mathrm{V}$, the equivariant case, the last equation can be written

$$
\begin{gathered}
d x / d t=\mathrm{K}(\mathrm{L}-x) \\
\text { where } \quad \mathrm{K}=h+\mathrm{N}+r \text { and } \mathrm{L}=h / \mathrm{K} .
\end{gathered}
$$

Now put $y=\mathrm{L}-x$ and we have $d y / y=-\mathrm{K} d t$.

4 "An Application of the Theory of Probabilities to the Study of a priori Pathometry." By Lieut.-Col. Sir Ronald Ross. Proc. Roy. Soc., A, Tgr6, xcii., 204.

NO. 2429, VOL. 97$]$
So that if $y_{0}$ is the value of $y$ at the beginning, $y=y_{0} e^{-\mathrm{K} t}$ and $x=\mathrm{L}-\left(\mathrm{L}-x_{0}\right) e^{-\mathrm{K} t}$,

which gives the proportion of the total population affected at time $t$, this proportion being $x_{0}$ when $t=0$.

Sir Ronald Ross proceeds to investigate the properties of this curve; he then takes the case of $v$ not equal to $\mathrm{V}$, which is dealt with on similar lines, and ultimately considers the curve arising in the simplest case of departure from the assumption that $h$ is constant. The latter results are, no doubt, still somewhat remote from the conditions obtaining in practice, but they suffice to illustrate the genesis of an asymmetrical curve, and incidentally show that a form regarded by Brownlee as inconsistent with an hypothesis of constant infectivity and the termination of an epidemic by the exhaustion of susceptible persons may not be so.

The advantage of Sir Ronald Ross's method, apart from its simplicity and elegance-advantages which are, however, no mean matterslies in its generality, so that it may be possible to include the case hypothesised by Brownlee as a particular example, precisely as Prof. Pearson's system of skew frequency curves included the normal curve as a special case. It is, of course, too early to speak with confidence. As restrictions are relaxed, the analysis will inevitably become more intricate, and, having evolved an a priori law, one must devise, usually by the method of moments, a way of applying the law to statistical data. This is work for the future, and all epidemiologists will await with interest the promised second part of Sir Ronald Ross's paper. No sensible man doubts the importance of such investigations as these; it is high time that epidemiology was extricated from its present humiliating position as the plaything of bacteriologists and public health officials, or as, at the best, a field for the display of antiquarian research. The work of Sir Ronald Ross, of Dr. Brownlee, and of a few others should at least elevate epidemiology to the rank of a distinct science.

\section{Greenwood, JR.}

\section{PROF. EMILE JUNGFLEISCH.}

DROF. EMILE JUNGFLEISCH, whose death occurred on Aprii 24, at the age of seventyseven, was born in Paris in 1839 He devoted himseif to chemistry and pharmacy, and at an early age joined the Paris Chemical Society. In r 863 he was appointed dispenser to the hospital of $\mathrm{La}$ Pitié, and in 1869 qualified as pharmacist and member (agrégé) of the School of Pharmacy. In the same year he became assistant (préparateur) to Berthelot, who had recently been appointed to the new chair of organic chemistry of the School of Pharmacy, and on Berthelot's retirement in 1876 was made his successor. In I89o Prof. Jungfleisch was nominated professor of chemistry of the Conservatoire des Arts et Métiers, and in I908, again in succession to Berthelot, was appointed to the chair of chemistry 